\title{
Technical Note: A numerical test-bed for detailed ice nucleation studies in the AIDA cloud simulation chamber
}

\author{
R. J. Cotton ${ }^{1}$, S. Benz ${ }^{2}$, P. R. Field ${ }^{1, *}$, O. Möhler ${ }^{2}$, and M. Schnaiter ${ }^{2}$ \\ ${ }^{1}$ Met Office, Exeter, Devon EX1 3PB, UK \\ ${ }^{2}$ Institute for Meteorology and Climate Research, Forschungszentrum Karlsruhe, Germany \\ *now at: National Center for Atmospheric Research (NCAR), Boulder, CO, USA
}

Received: 30 August 2006 - Published in Atmos. Chem. Phys. Discuss.: 27 September 2006

Revised: 19 December 2006 - Accepted: 11 January 2007 - Published: 18 January 2007

\begin{abstract}
The AIDA (Aerosol Interactions and Dynamics in the Atmosphere) aerosol and cloud chamber of Forschungszentrum Karlsruhe can be used to test the ice forming ability of aerosols. The AIDA chamber is extensively instrumented including pressure, temperature and humidity sensors, and optical particle counters. Expansion cooling using mechanical pumps leads to ice supersaturation conditions and possible ice formation. In order to describe the evolving chamber conditions during an expansion, a parcel model was modified to account for diabatic heat and moisture interactions with the chamber walls. Model results are shown for a series of expansions where the initial chamber temperature ranged from $-20^{\circ} \mathrm{C}$ to $-60^{\circ} \mathrm{C}$ and which used desert dust as ice forming nuclei. During each expansion, the initial formation of ice particles was clearly observed. For the colder expansions there were two clear ice nucleation episodes.

In order to test the ability of the model to represent the changing chamber conditions and to give confidence in the observations of chamber temperature and humidity, and ice particle concentration and mean size, ice particles were simply added as a function of time so as to reproduce the observations of ice crystal concentration. The time interval and chamber conditions over which ice nucleation occurs is therefore accurately known, and enables the model to be used as a test bed for different representations of ice formation.
\end{abstract}

\section{Introduction}

The ice formation mechanism, whether by homogeneous freezing of solution droplets or heterogeneous nucleation on insoluble aerosols, affects the properties of cirrus and mixedphase clouds. This is because, in the absence of secondary

Correspondence to: R. J. Cotton

(richard.cotton@metoffice.gov.uk) ice formation processes, such as the Hallet and Mossop (1974) rime-splintering mechanism, the initial ice nucleation mechanism determines the ice particle number concentration. The mean particle size and therefore precipitation, microphysical processes such as aggregation and particle growth, and cloud radiative properties are all affected by the initial ice nucleation.

There is evidence that even for temperatures colder than $-38 \mathrm{C}$, not all ice is produced by homogeneous freezing, a small amount of ice is sometimes formed by heterogeneous nucleation. Aircraft observations suggest that initial ice formation in mid-latitude cirrus can occur at relative humidities lower than the homogeneous freezing threshold (see Heymsfield et al., 1998). Seifert et al. (2003) showed that the size distribution of the residual aerosols after cirrus ice crystals have been evaporated was not that expected for homogeneous freezing alone. Aircraft observations of orographic wave clouds have also implied that ice crystals can be initiated by heterogeneous nucleation (Jensen et al., 1998; Field et al., 2001), although homogeneous freezing is the dominant process.

Particles that might initiate ice formation in cirrus clouds include black carbon soot, mineral dust and ammonium sulphate aerosols. Aircraft emissions, fossil fuel and biomass burning are sources of soot, while mineral dust is derived from the Earth's surface. Dust from the Saharan desert advected across the Atlantic was observed to act as ice nuclei in the aircraft campaign CRYSTAL-FACE (Cirrus Regional Study of Tropical Anvils and Cirrus Layers - Florida Area Cirrus Experiment) (Sassen et al., 2003; DeMott et al., 2003; Cziczo et al., 2004). Analysis of the ice crystal residuals from the aircraft campaign INTACC (Interaction of Aerosol and Cold Clouds) described in Targino et al. (2006) showed that when heterogeneous nucleation was observed, mineral dust was more prevalent. Roberts and Hallet (1968) showed that desert dust can be good deposition nuclei.

Kärcher and Lohmann (2003) developed a parametrisation

Published by Copernicus GmbH on behalf of the European Geosciences Union. 
of cirrus cloud formation by heterogeneous nucleation and considered possible ice nuclei properties. They concentrate on immersion freezing as the dominant heterogeneous nucleation mode for cirrus formation at cold temperatures $(<235 \mathrm{~K})$.

The heterogeneous ice nucleating ability of desert dust samples was investigated in the AIDA (Aerosol Interactions and Dynamics in the Atmosphere) aerosol and cloud chamber. This allows the aerosol concentration and size distribution, and the ambient temperature, pressure, humidity and rate of cooling to be controlled and made similar to upper troposphere conditions. Haag et al. (2003) showed the relevance of AIDA for cirrus studies by using numerical simulations of homogeneous freezing processes in the AIDA chamber. The measured temperature, pressure and total water time-series was used to constrain the model, and the measured initial aerosol size distribution was an input. The homogeneous freezing process and partitioning of water between gas and ice phase was explicitly simulated and tested by the model. Prescribing the temperature, pressure and total water histories, eliminates the need for the heat and vapour fluxes from the chamber walls to the bulk gas. A different way to describe the evolving chamber conditions during an expansion is to run an parcel model with diabatic terms representing heat and water vapour flux terms which are derived from observations. This method leads to a more self-consistent model and is the basis for this paper.

Firstly, ice particles are added to the model as a function of time so as to reproduce the observations of ice crystal concentration. The agreement between the model and the observations of chamber relative humidity and temperature, and of the ice particle concentration and average diameter improves the confidence in these measurements and in the estimates of the wall fluxes of heat and water vapour. The time interval and chamber conditions over which ice nucleation occurs is therefore accurately known. By establishing the ability of the model to describe the evolving chamber conditions, it can then be used as a test bed for different representations of heterogeneous ice nucleation. Ice particles can then be initiated by means of explicit nucleation acting on aerosol, in order to determine whether or not the simulated process is consistent with the observations.

In Sect. 2 the operation of the AIDA aerosol and cloud chamber is described. Section 3 describes the chemical composition and size distribution of the desert dust samples. Section 4 describes the instrumentation that is used in this study. Section 5 describes the microphysics model with wall heat and vapour fluxes. Section 6 presents a series of observations together with the model results, a summary of the chamber conditions for which the ice particles are initiated. The conclusions are then in Sect. 7.

\section{The AIDA chamber and the experimental procedure}

A detailed description of the AIDA chamber, the instruments, and the experimental procedure are described in Möhler et al. (2003). AIDA is a large cylindrical chamber made of $2 \mathrm{~cm}$ thick aluminium walls, within a thermally isolated containment. The chamber is $7 \mathrm{~m}$ high, has a diameter of $4 \mathrm{~m}$ and a volume of $84 \mathrm{~m}^{3}$. The interior of the containment can be cooled and maintained to any temperature between ambient and $-90^{\circ} \mathrm{C}$ by ventilation of air cooled in heat exchangers. This containment defines the initial temperature in the aerosol chamber. A fan within the chamber achieves a wellmixed environment where the inhomogeneity in temperature is less than $\pm 0.2 \mathrm{~K}$ and the humidity variability is less than $\pm 3 \%$. The chamber pressure is controlled by two large mechanical pumps.

Typically the chamber is operated so that there are several ice nucleation experiments during the day, each using the same aerosol sample. First, the chamber is cleared of any aerosols from previous experiments by pumping down to below $1 \mathrm{hPa}$ and flushed with dry synthetic particle free air. A controlled amount of water vapour is then added to the evacuated chamber which is then filled with dry synthetic air to atmospheric pressure. This leads to an aerosol background concentration of less than $0.1 \mathrm{~cm}^{-3}$. The chamber is then cooled slowly to the experiment starting temperature using the thermal containment heat exchangers. Once the gas temperature falls below the frost point, water vapour deposits onto the chamber walls. The ice coating on the chamber walls means that the vapour pressure immediately next to the wall is the ice saturation vapour pressure. Heat, from the mixing fan in the chamber means that the gas temperature is slightly higher than the wall temperature, and therefore all experiments start at just below ice saturation. This ice coating is not uniform over all the chamber walls. Expansion cooling using mechanical pumps then leads to ice supersaturation conditions. The pumping rate can be varied, but typically the pressure is reduced from $1000 \mathrm{hPa}$ to $800 \mathrm{hPa}$ over a few minutes. The equivalent ascent rates are from $1 \mathrm{~ms}^{-1}$ to $10 \mathrm{~ms}^{-1}$, and enable both orographic wave clouds, where updrafts of up to $5 \mathrm{~ms}^{-1}$ (Jensen et al., 1998; Field et al., 2001) have been observed, and the lesser convective updrafts in cirrus generating cells up to to be simulated. The chamber pressure is however, substantially higher than in cold cirrus. Even higher rates of expansion cooling can be reached for short time periods by expansion into an evacuated volume of about $4 \mathrm{~m}^{3}$. (The expansions $19-21$ reach $20 \mathrm{~ms}^{-1}$ as shown in Table 1.) The first expansion is carried out with no aerosol sample in the chamber in order to characterise the background conditions. After adding the aerosol sample, the number concentration and size distribution is measured using standard aerosol instrumentation.

The cooling rate deviates from that expected if the expansion was adiabatic. This is caused by the increasing heat flux from the $2 \mathrm{~cm}$ thick aluminium chamber walls. (See 
Table 1. Experiment list grouped into four temperature regimes. The ice concentrations are the SID non-spherical concentration increased by a factor of 1.4. For expansions $27-29,40-42$ and 22-24 there is a second ice initiation phase.

\begin{tabular}{|c|c|c|c|c|c|c|c|c|}
\hline \multirow[t]{2}{*}{ Expansion } & \multirow{2}{*}{$\begin{array}{l}\text { Dust } \\
\text { sample }\end{array}$} & \multirow{2}{*}{$\begin{array}{l}\text { Initial } \\
\text { aerosol } \\
\left(\mathrm{cm}^{-3}\right)\end{array}$} & \multirow{2}{*}{$\begin{array}{l}\text { Equivalent } \\
\text { updraft } \\
\left(\mathrm{ms}^{-1}\right)\end{array}$} & \multirow{2}{*}{$\begin{array}{l}K_{T} \\
()\end{array}$} & \multicolumn{2}{|c|}{ First ice nucleation mode } & \multicolumn{2}{|c|}{ Second ice nucleation mode } \\
\hline & & & & & $\begin{array}{l}\text { Temperature } \\
\left({ }^{\circ} \mathrm{C}\right)\end{array}$ & $\begin{array}{l}\text { Ice concentration } \\
\left(\mathrm{cm}^{-3}\right)\end{array}$ & $\begin{array}{l}\text { Temperature } \\
\left({ }^{\circ} \mathrm{C}\right)\end{array}$ & $\begin{array}{l}\text { Ice concentration } \\
\left(\mathrm{cm}^{-3}\right)\end{array}$ \\
\hline \multicolumn{9}{|c|}{ Temperature regime I: Single nucleation mode } \\
\hline 44 & SD2 & 38.4 & $4.0-3.0,2.5-2.0$ & 3.7 & -60.7 & 42.5 & & \\
\hline 45 & SD2 & 9.0 & $4.0-3.0,2.0-2.0$ & 3.7 & -60.6 & 8.7 & & \\
\hline \multicolumn{9}{|c|}{ Temperature regime II: Two overlapping ice nucleation modes } \\
\hline 26 & AD1 & 99.3 & $5.2-4.0$ & 3.8 & -51.7 & 21.5 & & \\
\hline 27 & AD1 & 60.2 & $5.2-4.0$ & 3.8 & -52.0 & 3.0 & -54.6 & 13.5 \\
\hline 28 & AD1 & 36.4 & $4.0-2.8$ & 3.8 & -52.4 & 1.3 & -55.2 & 4.6 \\
\hline 29 & $\mathrm{AD} 1$ & 24.1 & $4.0-2.8$ & 4.1 & -52.4 & 1.1 & -55.7 & 3.8 \\
\hline 40 & SD2 & 89.4 & $4.5-4.0$ & 4.0 & -50.8 & 2.5 & -52.4 & 12.2 \\
\hline 41 & $\mathrm{SD} 2$ & 53.3 & $4.0-3.5,2.4-2.3$ & 4.1 & -50.9 & 0.5 & -53.1 & 7.5 \\
\hline 42 & SD2 & 32.4 & $4.0-3.2,2.5-2.3$ & 4.0 & -50.6 & 0.3 & -53.6 & 6.7 \\
\hline \multicolumn{9}{|c|}{ Temperature regime III: Two separate ice nucleation modes } \\
\hline 22 & AD1 & 115.9 & $6.0-4.3$ & 4.3 & -39.8 & 0.5 & -40.7 & 12.0 \\
\hline 23 & AD1 & 78.8 & $6.0-4.2$ & 4.2 & -40.2 & 0.8 & -42.2 & 7.0 \\
\hline 24 & AD1 & 56.8 & $7.0-5.0$ & 4.2 & -38.9 & 1.0 & -41.8 & 12.2 \\
\hline 25 & $\mathrm{AD} 1$ & 37.3 & $4.5-3.0$ & 3.9 & -39.0 & 0.5 & & \\
\hline \multicolumn{9}{|c|}{ Temperature regime IV: Single nucleation mode, Liquid water observed } \\
\hline 18 & AD1 & 180.6 & $11.0-8.5$ & 4.5 & -28.4 & 10.0 & & \\
\hline 19 & AD1 & 129.2 & $20.0,10.0-8.0$ & 4.3 & -29.2 & 10.5 & & \\
\hline 20 & AD1 & 89.1 & $20.0,9.5-8.5,1.5-2.0$ & 4.3 & -30.9 & 4.3 & & \\
\hline 21 & AD1 & 63.8 & $20.0,9.5-8.5,1.5-2.0$ & 4.4 & -31.6 & 4.0 & & \\
\hline
\end{tabular}

Möhler et al. (2005) for a discussion of the heat fluxes.) Figures $1 \mathrm{a}$ and $1 \mathrm{~b}$ shows the chamber pressure and the resultant cooling for an example chamber expansion. The equivalent updraft of an adiabatic air parcel undergoing the chamber cooling rate is also shown, and is given by,

$w=-\frac{C_{p}}{g} \frac{d T_{g}}{d t}$

where $T_{g}$ is the chamber bulk gas temperature. The updraft, $w$, is used to force the parcel model. The wall temperature remains approximately constant during the pumping due to the large heat capacity of the chamber walls. Eventually the gas temperature reaches an equilibrium value where the expansion cooling and the heat flux from the warmer walls balance.

During the expansion cooling there is also a water vapour flux from the ice coated chamber walls into the gas volume. For some expansions, the change in total mixing ratio is comparable to the condensate mixing ratio, (Fig. 1c). Because the wall temperature is always almost constant during the expansions, the water vapour pressure above the ice-coated chamber walls is also constant. The vapour pressure in the bulk gas, however, is reduced by the decreasing pressure and tem- perature during the expansion. Once liquid or ice particles are formed, the particle diffusional growth also reduces the bulk gas water vapour pressure. This varying difference in vapour pressure leads to a water vapour flux from the chamber walls to the bulk gas. During the chamber expansion the total water mixing ratio is therefore not constant.

\section{Aerosol description}

Two dust samples were collected from the ground, in the Takla Makan desert in China (referred to as Asian dust AD1) and north of Cairo city (Saharan dust SD2). The details of the elemental composition and aerosol size spectra are in Möhler et al. (2006). X-ray fluorescence analysis showed that silicon, aluminium and calcium oxides where abundant. The aerosols which were added to the chamber were selected by dry dispersion of the dust samples and inertial removal of particles greater than $2 \mu \mathrm{m}$ diameter. The size distributions of the aerosols were approximately log-normal with a range between 0.1 and $2 \mu \mathrm{m}$, mode diameter of 0.3 to $0.5 \mu \mathrm{m}$ and standard deviation of 1.6 to 1.9 . 


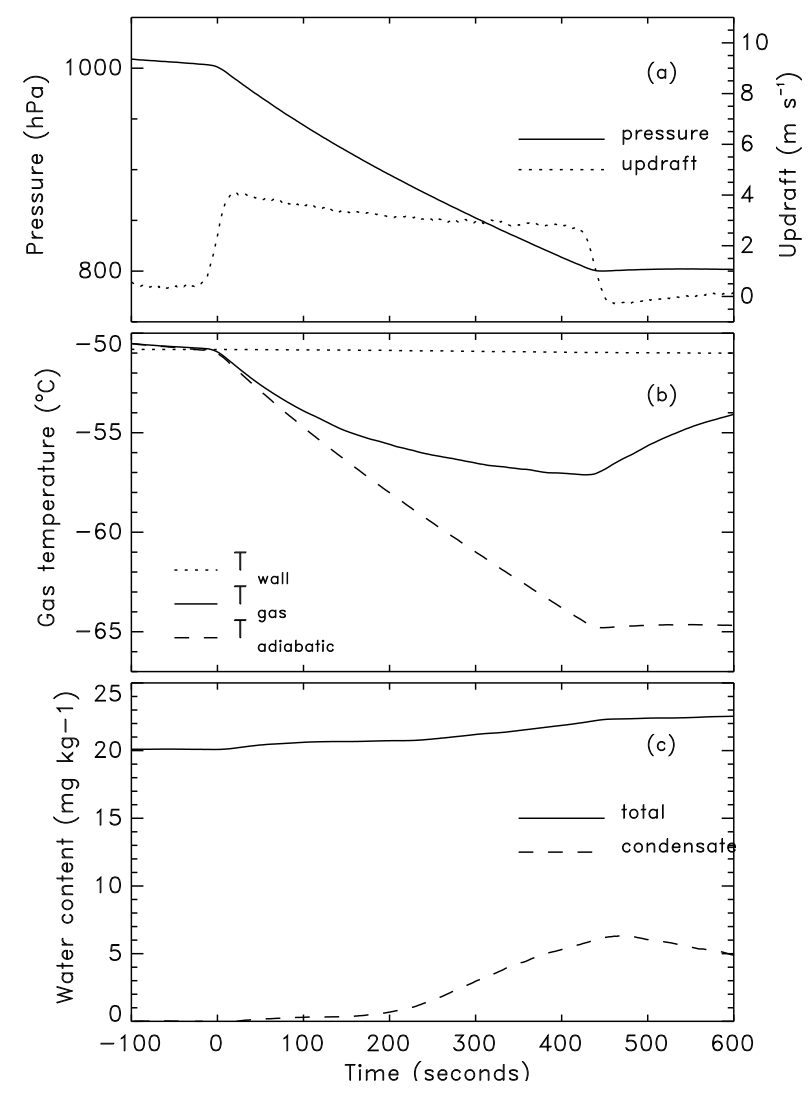

Fig. 1. An example chamber expansion (experiment 28) showing the chamber pressure change (a), and the resultant cooling (b). The effect of the wall vapour flux is shown in panel (c). The time axis is plotted in seconds relative to the start of pumping. There is also a decrease in chamber pressure before the actual expansion starts due to the particle probes sampling the chamber gas.

\section{Instrumentation}

The AIDA chamber is extensively instrumented including pressure, temperature and water vapour sensors, and optical particle counting probes and aerosol characterisation devices (see Möhler et al., 2003 and Möhler et al., 2005). The gas and chamber wall temperatures are measured with an array of platinum resistance thermometers and thermocouples. The variation between all measured temperatures is less than $\pm 0.3 \mathrm{~K}$. The instruments used in this study are the total water and water vapour sensors, aerosol characterisation and the small ice detector (SID).

\subsection{Total water mixing ratio}

A chilled mirror hygrometer (MBW) measures the frost point. The chamber air is sampled through a heated tube so that any ice or liquid particles are rapidly evaporated and hence this instrument can be used to measure the total water mixing ratio in the chamber.
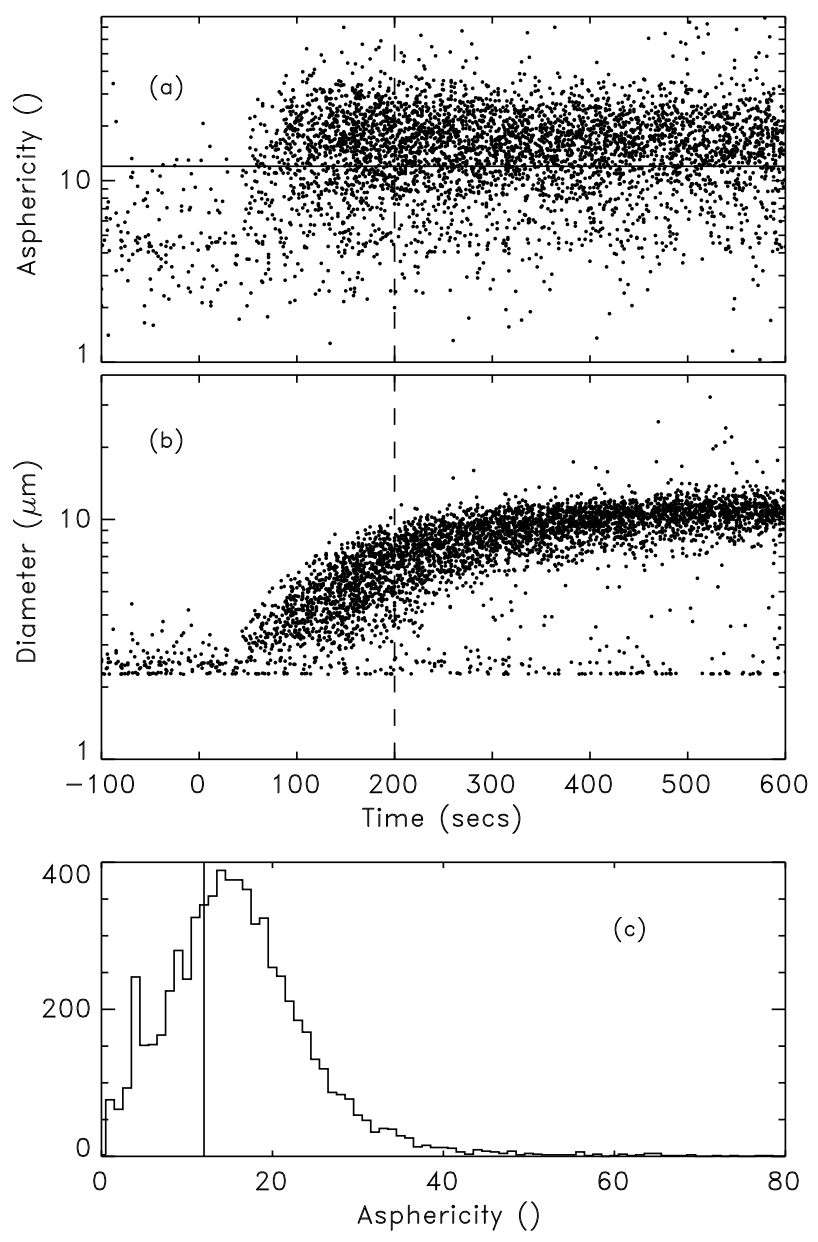

Fig. 2. SID measurements for expansion 45 (Saharan dust, where the chamber gas temperature decreased from $-60^{\circ} \mathrm{C}$ to $-65^{\circ} \mathrm{C}$ ). (a) shows the asphericity, $A_{f}$, for every particle sampled, (b) the diameter, and (c) a histogram of $A_{f}$ for particles sampled after $200 \mathrm{~s}$.

The sampling efficiency is estimated to be $100 \%$ for ice and liquid particles below $7 \mu \mathrm{m}$ diameter. As long as the total ice water content is small compared to the total water content the error from not sampling all the larger ice particles is small. For the expansions shown here, this is the case because the total number concentration of ice particles is low. Additionally, the important model phase is the ice nucleation time-period and the ice particles are small (but growing). Figure 4 shows an expansion where during the nucleation interval, most ice particles are less than $7 \mu \mathrm{m}$ and also the total condensate mass mixing ratio is an order of magnitude less than the water vapour mixing ratio. Figure 5 shows many ice particles above $7 \mu \mathrm{m}$ during the second ice nucleation mode, but the total condensate mixing ratio is still an order of magnitude less than the water vapour. Figure 6 shows lots of large ice particles present (just after the ice nucleation), and 
the relative humidity will be underestimated. The possible underestimate of relative humidity, however, does not change the conclusions regarding the ability to model the onset of ice nucleation. For the conditions observed here, the frost point accuracy is estimated to be $\pm 0.1 \mathrm{~K}$.

\subsection{Water vapour}

The water vapour pressure inside the chamber is directly measured by a tunable diode laser (TDL) hygrometer. In order to significantly reduce systematic errors caused by uncertainties in the absorption lines, the TDL is corrected by comparison with the cooled mirror hygrometer prior to each expansion. The estimated error is $\pm 1.3 \%$ at $220 \mathrm{~K}$ to $\pm 1.7 \%$ at $190 \mathrm{~K}$, which for the ice saturation ratio is $\pm 4.0 \%$ at $220 \mathrm{~K}$ and $\pm 6 \%$ at $190 \mathrm{~K}$. For this study, the TDL water vapour is used only as a consistency check after the model has run. In future studies, the corrected TDL water vapour might be used directly as an input to the model, similar to how the pressure is used.

\subsection{Aerosols}

The aerosol number concentration is measured by a condensation particle counter (CPC) where particles less than $2 \mu \mathrm{m}$ diameter are sampled with $100 \%$ efficiency. Ice particles that are formed during the chamber expansion evaporate in the warm sample tube. When the ice particles are formed on insoluble aerosols, the residual after evaporation can enter the CPC. The non-quantified size dependent loss in the sampling tube, however, means that the total aerosol concentration when there are ice particles present has a large error.

\subsection{Small particle phase, size and concentration}

Particle concentrations and mean particle size are measured using a laser scattering device, the small ice detector (SID), described by Hirst et al. (2001). The SID can count and size particles above $1 \mu \mathrm{m}$ diameter and discriminate between liquid water drops and ice particles. The probe has six photodetectors arranged azimuthally at a $30^{\circ}$ forward scattering angle. One photo-detector acts as a trigger, and the variation in the signals from the other five photo-detectors is used to determine the particle phase. The photo-detector signal variation is specified by an asphericity factor, $A_{f}$, defined by

$A_{f}=k \frac{\sqrt{\sum_{i=1,5}\left(<E>-E_{i}\right)^{2}}}{<E>}$

where $E_{i}$ is the i'th photo-detector signal, and $\mathrm{k}$ is a constant set so that $A_{f}$ is in the range $0-100$. Spherical liquid water drops scatter the laser uniformly in azimuth and therefore should give a low asphericity value. Ice particles, which are non-spherical, scatter the laser non-uniformly and therefore give a high apshericity. A nominal threshold of $A_{f}=12$ is chosen (this allows good discrimination between liquid water

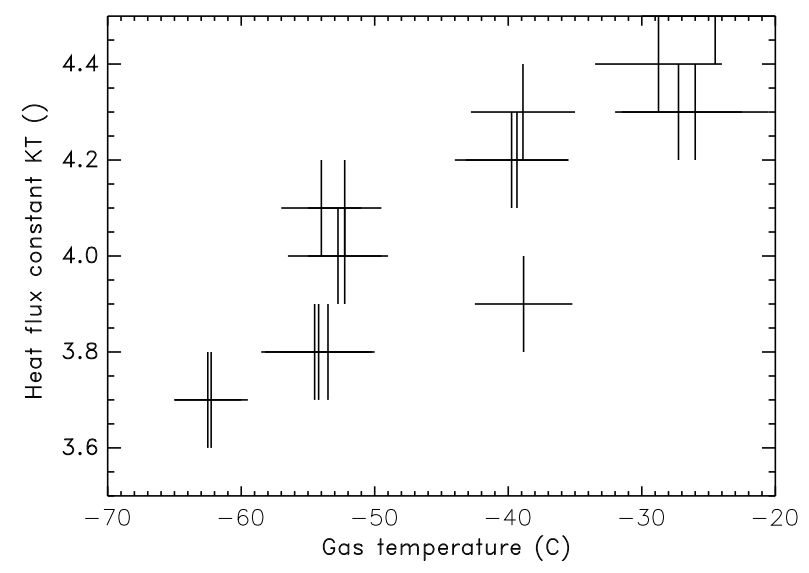

Fig. 3. Empirically derived $K_{T}$ for each chamber expansion.

drops and ice particles from in-situ aircraft observations in Stratocumulus and Cirrus clouds).

The particle radius, $R$, is derived from the mean photodetector signal using the power law,

$R=a<E>^{0.51}$

where $a$ is estimated by comparing the measured bulk liquid water content obtained with hot wire probes in Stratocumulus cloud with that obtained by the SID. The SID size estimation is therefore only correct for spherical liquid droplets.

Because of the detector noise, not all small ice particles have an asphericity above the $A_{f}=12$ threshold. This is shown in Fig. 2 which is one of the coldest expansions using Saharan desert dust where the chamber gas temperature decreased from $-60^{\circ} \mathrm{C}$ to $-65^{\circ} \mathrm{C}$. In Fig. 2a, the solid line at $A_{f}=12$ is drawn to separate the non-spherical from the spherical particles. The particle diameters in Fig. $2 b$ show the ice crystals being initiated between about 30 and $160 \mathrm{~s}$. The SID particle diameter is only calibrated for spherical particles, but does indicate the trend towards increasing nonspherical particle diameter. In Fig. 2c, the histogram of $A_{f}$ for the particles sampled after $200 \mathrm{~s}$, shows that around $70 \%$ of the small ice particles are classified as non-spherical. In the modelling studies described here, the SID non-spherical concentration is therefore increased by a factor of 1.4.

\section{Parcel model with heat and vapour fluxes}

The parcel model is a detailed microphysics size-resolving model modified to include heat and vapour fluxes from the chamber walls. The unmodified parcel model (described in detail in Cotton and Field (2002) considers an adiabatic parcel of air containing a conserved mass of water being lifted by a variable updraft. The parcel model was also used in the Cirrus Parcel Model Comparison (CPMC) project as part of 

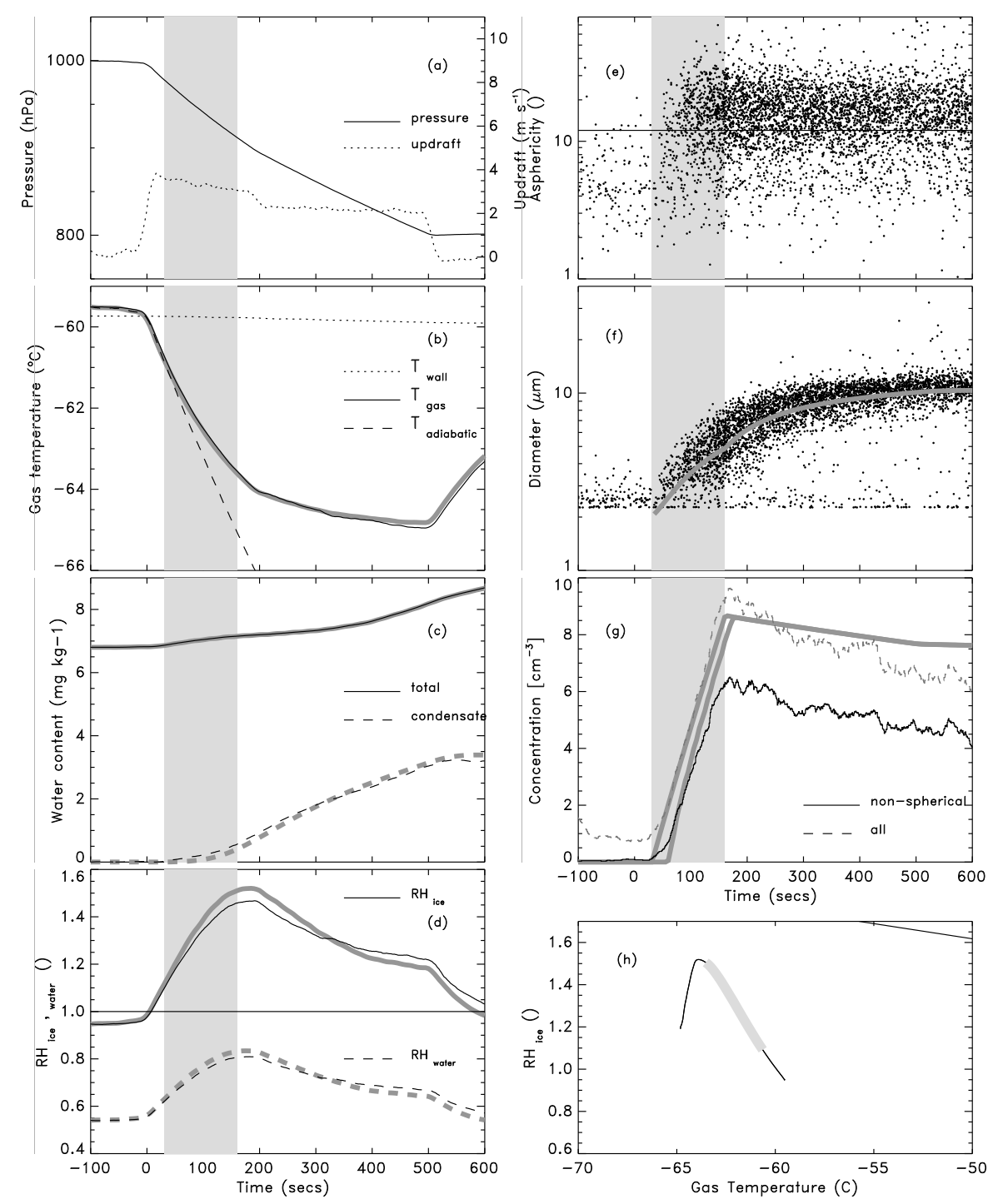

Fig. 4. Temperature regime I: Single nucleation mode. Model-observation comparison for Saharan dust (Expansion 45). The expansion starts at $0 \mathrm{~s}$. Only one ice nucleation mode is observed with ice particles initiated between 30 and $160 \mathrm{~s}$, as indicated by the light grey vertical shading. The two thick grey lines on panel (g) are the model concentration for all ice particles, and for ice particles with diameter greater than $3 \mu \mathrm{m}$.

the GEWEX Cloud System Studies on cirrus clouds (GCSS WG2) which compared results from various parcel models over a range of updraft velocities and CCN spectrum (see Lin et al., 2002). The vapour pressures of water over ice and supercooled water are the updated (1957) Goff derivations (see Murphy and Koop., 2005 and references therein).

For the model initialisation, we simply assume that all the aerosol measured in the AIDA chamber using the CPC can act as CCN. The dry CCN size spectrum was lognormally distributed between 0.1 and $2.0 \mu \mathrm{m}$ diameter, with a mode of $0.4 \mu \mathrm{m}$, with the total concentration given by the initial $\mathrm{CPC}$ aerosol concentration. All chamber expansions were modelled with this $\mathrm{CCN}$ distribution, and were allowed to deliquesce and if the humidity is high enough activate to drops. The SID probe will not necessarily detect all the larger aerosols because the size threshold for detection is for liquid drops, not dry aerosol. The effect of including the CCN was only important for expansions 18-21 (listed in Table 1) where liquid drops were observed before any ice particles.

\subsection{Wall heat flux}

The wall heat flux contributes to the rate of change of gas temperature. The heat flux diabatic term is assumed to be proportional to the temperature difference between the gas and chamber wall,

$$
\left.\frac{d T_{g}}{d t}\right|_{\text {wallflux }}=\frac{K_{T}}{C_{p}}\left[T_{w}-T_{g}\right]
$$



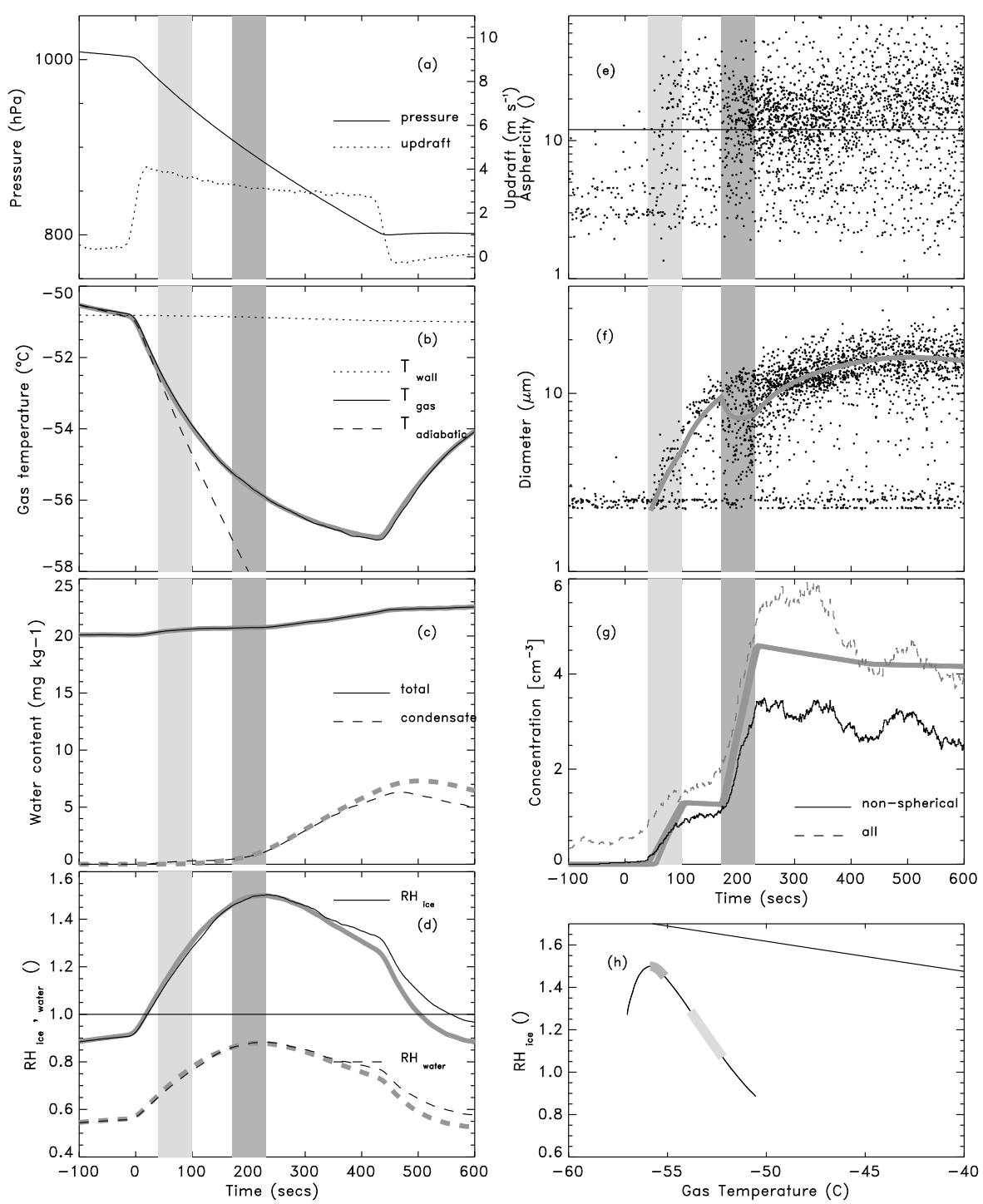

Fig. 5. Temperature regime II: Two ice nucleation modes. Model-observation comparison for Asian dust (Expansion 28). There are two distinct nucleation modes, with ice initiated between 40 and $100 \mathrm{~s}$ and between 170 and $230 \mathrm{~s}$, as indicated by the light and dark grey vertical shading.

where $K_{T}$ is simply chosen on an expansion by expansion basis to give the best fit to the gas temperature. The detailed physics of the heat flux is contained within $K_{T}$. Figure 3 shows the $K_{T}$ term for each expansion. The horizontal error bar represents the range of temperature observed during the expansion, the vertical bar is the estimated error on $K_{T}$. There is a good correlation of $K_{T}$ with temperature.

\subsection{Wall water vapour flux}

The water vapour flux contributes to the rate of change of total water mixing ratio, $q_{T}$. The water vapour flux can be included in different ways. The first is analogous to the formulation of the wall heat flux, i.e. the vapour flux is pro- portional to the difference in vapour pressure just above the chamber wall and in the bulk gas,

$\left.\frac{d q_{T}}{d t}\right|_{\text {wallflux }}=K_{V} \frac{0.622}{P \rho_{\text {air }}}\left[e_{s, i}\left(T_{w}\right)-\sigma_{i} e_{s, i}\left(T_{g}\right)\right]$

where $K_{V}$ is a constant, $e_{s, i}$ is the ice saturation vapour pressure and $\sigma_{i}$ is the ratio of the ice vapour pressure in the bulk gas to the ice saturation vapour pressure. Because the wall temperature, $T_{w}$, is always almost constant during the expansions when the chamber wall is completely ice-coated, the saturation vapour pressure, $e_{s, i}\left(T_{w}\right)$, is also constant. This parametrisation does not work well for all chamber expansions. 

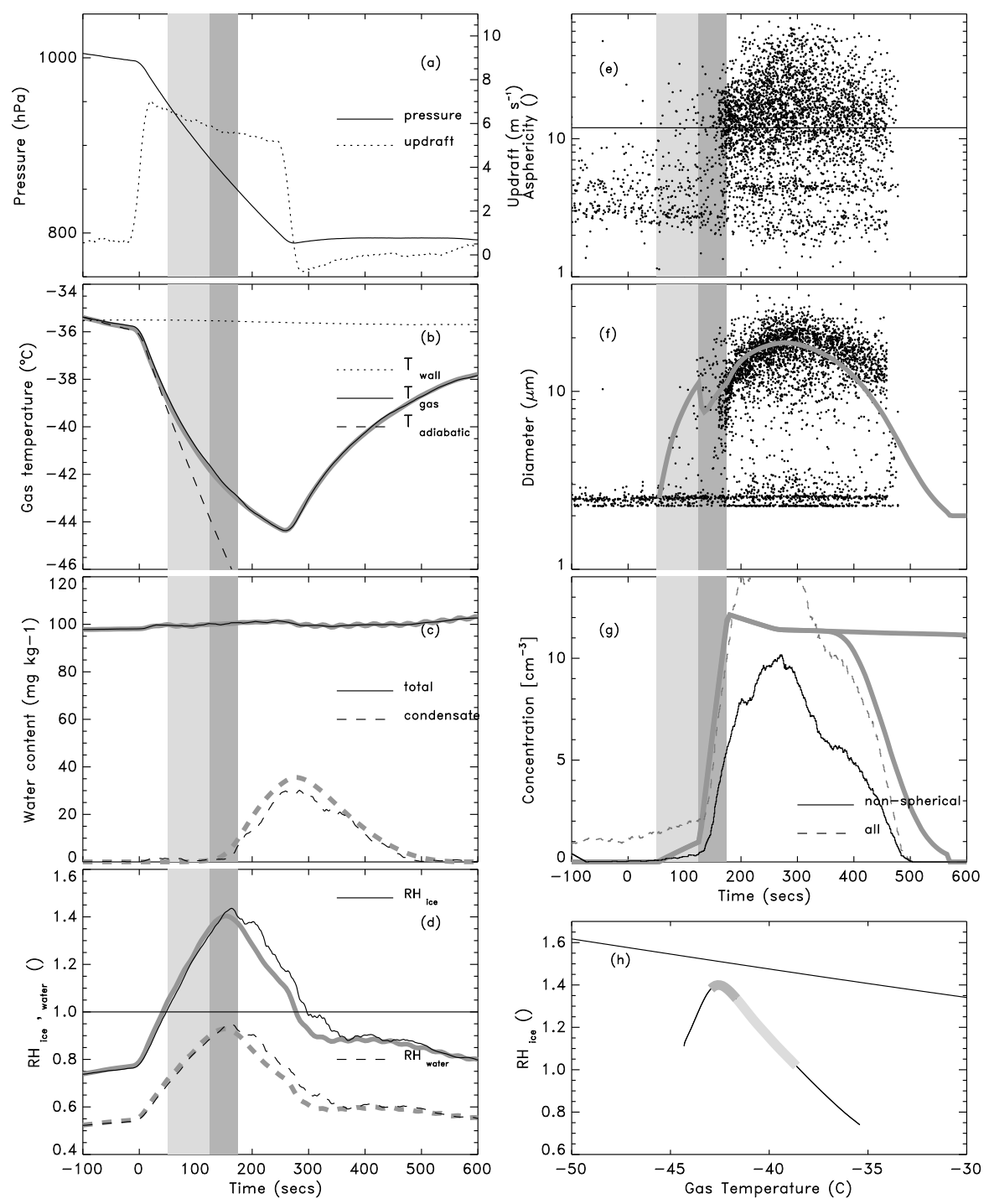

Fig. 6. Temperature regime III: Two nucleation modes. Model-observation comparison for Asian dust (Expansion 24). There are two nucleation modes, but they are not as distinct as for expansion 28. The two thick grey lines on panel (g) are the model concentration for all ice particles, and for ice particles with diameter greater than $3 \mu \mathrm{m}$.

A second approach is to calculate the vapour flux from the heat flux assuming a boundary layer. This will be expanded further in a later paper.

An alternative approach to parametrising the wall vapour flux is to assume that the MBW hygrometer measures the chamber total water mixing ratio accurately. This is reasonable since significant errors are expected only when the total condensate mass is large compared with the water vapour mixing ratio. So the presence of large ice particles does not necessarily invalidate this method. In all of the expansions, especially during the ice initiation phase, the total condensate mass mixing ratio is an order of magnitude less than the water vapour mass mixing ratio, and therefore any error in not sampling large particles is negligable. While Fig. 5 and
Fig. 6 both show large ice particles and therefore a significant condensate mass mixing ratio, it is mostly after the ice nucleation phase. Here the MBW sampling inefficiency of large ice particles leads to the small discrepency in condensate mass mixing ratio, but this does not affect the conclusion regarding the ability to model the expansion during the ice initiation phase.

The model is constrained by the measured total water content at each time-step during the expansion. Any differences in ice concentration between model and chamber will result in a different partitioning of the total water between ice and vapour. This will in turn be manifested as a difference between the model vapour mixing ratio and that measured by the TDL. For only some of the expansions, each water vapour 
flux method gives similar results. The reason for the discrepency between the different methods for most of the expansions is due to the fact that the ice layer on the chamber walls is not uniform and that not all the chamber surface is covered with ice. The third method is used for the results described here.

\subsection{Ice initiation method}

In order to test the ability of the model to reproduce the observations, ice particles may be added to the model as a function of time so as to reproduce the SID particle number concentration (scaled by 1.4), rather than initiating ice particles by means of explicit nucleation acting on aerosol. The ice particles are initiated in the smallest ice particle size bin $(0.1 \mu \mathrm{m})$. When run in this way, the model is then providing a test of the assumptions used within it which determine the diffusional growth rate of ice. These include the crystal capacitance and the water vapour accommodation coefficient. If these parameters were grossly in error, the model would not reproduce the observed water vapour evolution even when constrained to the observed total water and ice initiation. Because the ice crystals are less than a few tens of micron diameter and there is no habit information, the crystals are assumed to be sphere. The capacitance is always assumed to be 1.0 and the ice density is $1.0 \mathrm{~g}, \mathrm{~cm}^{-3}$. The ice deposition coefficient is 0.24 , following Sassen and Dodd (1988). The sensitivity to the capacitance and deposition coefficient is shown in Sect. 6.6.

\section{Observations and model results}

Table 1 lists some details of the chamber expansions for both dust samples, with the chamber temperature covering a range of $-20^{\circ} \mathrm{C}$ to $-65^{\circ} \mathrm{C}$. The expansions are divided into four temperature regimes. For the first, regime I (expansions 44-45) only one nucleation mode is observed, while for regimes II and III (expansions 26-42 and 22-25) two nucleation modes are generally observed. The last, regime IV (expansions 18-21) reaches water saturation, and liquid water is observed. This division in regimes is done just for organisational purposes and no assumption is made that different ice nucleation modes occur in each regime, and in fact there is a continuum of behavior in regimes II and III.

Figures 4-7 show the modeled and observed data from example chamber expansions, one from each of the four temperature regimes. Panel (a) shows the chamber pressure and equivalent updraft. In all cases, the start of the expansion is at zero seconds. Prior to this, the pressure decreases very slowly due to the continuous sample flow through the particle probes. The pressure change has been converted into an updraft assuming adiabatic expansion in order to force the parcel model. The pumping rate during each expansion was often varied, giving a step-change in the equivalent updraft.
Panel (b) shows the chamber bulk gas and wall temperatures. The wall temperature is constant but the bulk gas temperature deviates from that expected if the expansion was adiabatic because of the significant wall to bulk gas heat flux. However, the modeled gas temperature (the thicker grey line) using a parametrised heat flux with a constant $K_{T}$ as defined by Eq. (4) enables a good match with the observations. Panel (c) shows the mass mixing ratio of the total water content (measured using the MBW) and the total condensate mixing ratio calculated as the difference between the total and water vapour mixing ratio (measured using the TDL). The model is constrained to follow exactly the total water content measurement. The pressure (and hence updraft), temperature and total water mixing ratio have been adjusted to fit, so there is no surprise about the good agreement. The condensate mixing ratio depends, however, on the validity of the model microphysics. Panel (d) shows the observed and modeled relative humidity w.r.t. ice, $\mathrm{RH}_{\mathrm{ice}}$, and w.r.t. water, $\mathrm{RH}_{\text {water }}$. The agreement with the TDL derived humidity is confirmation that the model correctly partitions the water between vapour and condensate. The chamber humidity starts just below ice saturation because of heat sources within the bulk gas (mainly mixing fans). For some expansions the chamber walls were not coated in ice and the initial humidity starts much lower than ice saturation. Panel (e) shows the measured asphericity factor, $A_{f}$, of all particles sampled by the SID. The line $A_{f}=12$ is drawn to separate the nonspherical from the spherical particles. Panel (f) shows the SID particle diameter together with the modeled mean diameter (thick grey line). Panel (g) shows the SID particle concentrations, for non-spherical $\left(A_{f}>12\right.$, solid line) and for all particles (dashed line), averaged over 10 second timeintervals. The modeled ice particle concentration, where the diameter is greater than $3 \mu \mathrm{m}$ and for all sizes above $1 \mu \mathrm{m}$, are shown by the two thick grey lines. The SID $A_{f}$ does not discriminate the particle phase for diameterss below around $3 \mu \mathrm{m}$.

The onset and duration of ice nucleation is estimated from the broad swath of SID particle diameters and from the SID non-spherical particle concentration. The light grey vertical shading just indicates this ice particle initiation time interval. If there is also a second distinct ice nucleation mode, this is indicated by a darker grey band. The ice nucleation scheme in the model simply initiates ice particles at a constant rate, shown in panel (g) (thick grey lines) through this time interval, so that at the end the ice crystal concentration matches the SID non-spherical particle concentration scaled by 1.4 (as listed in Table 1). Panel (h) shows the evolution of $\mathrm{RH}_{\text {ice }}$ with temperature during the cooling (expansion) phase. The thick grey shading on the curve indicates the period when ice crystals are added to the model. The model temperature and humidity is used because of uncertainties in the measured humidity. 

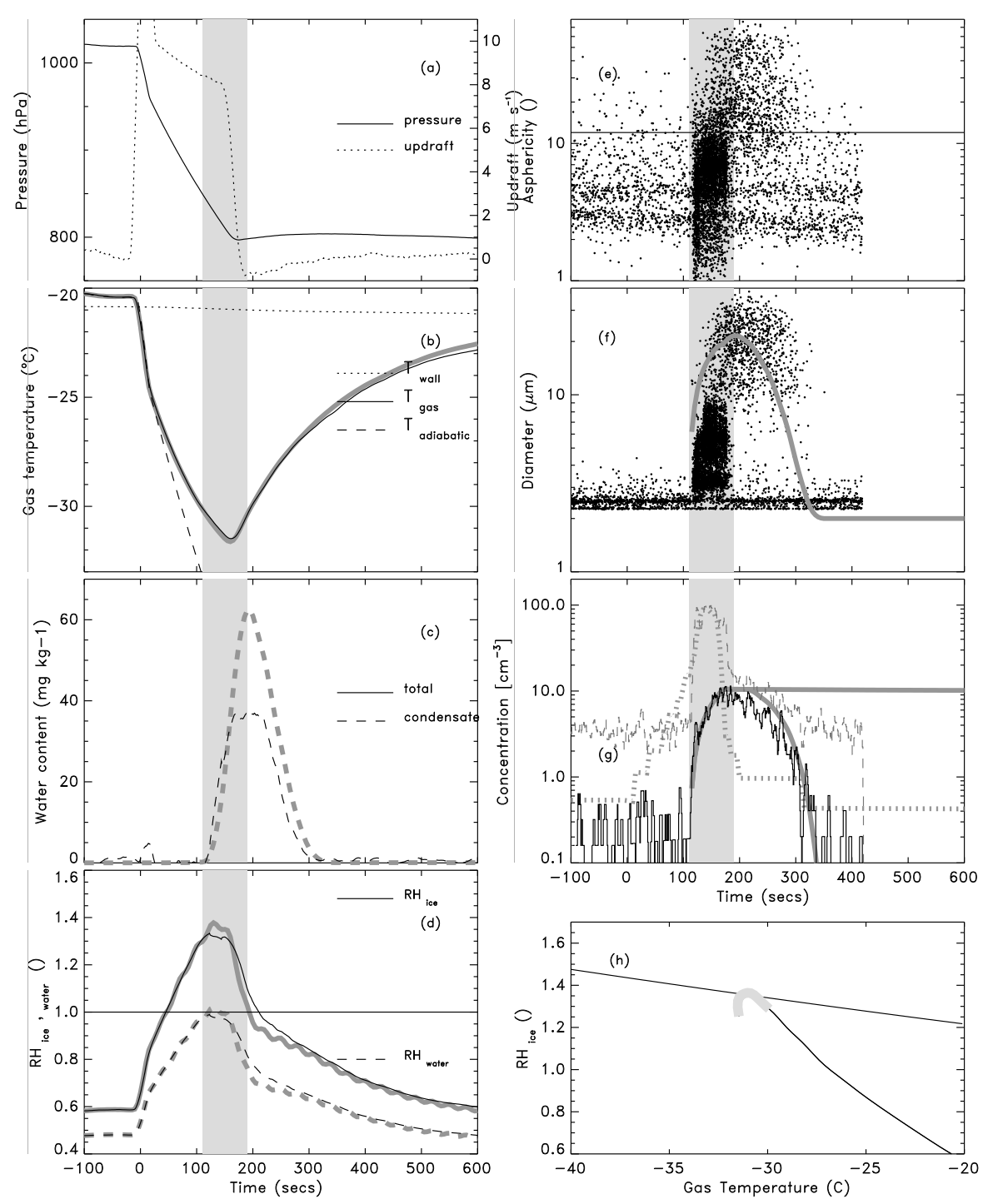

Fig. 7. Temperature regime IV: One nucleation mode, liquid water observed. Model-observation comparison for Asian dust (Expansion 19). Note that panel (g) now has a logarithmic scale in order to more clearly show both liquid and ice concentrations. The two thick grey lines on panel $(\mathrm{g})$ are the model concentration for all ice particles, and for ice particles with diameter greater than $3 \mu \mathrm{m}$. The thick dashed grey line is the model drop concentration with diameter greater than $3 \mu \mathrm{m}$.

\subsection{Temperature regime I: single nucleation mode}

Figure 4 shows the coldest expansion using Saharan desert dust (Expansion 45) where the chamber gas temperature decreased from $-60^{\circ} \mathrm{C}$ to $-65^{\circ} \mathrm{C}$. At $200 \mathrm{~s}$, the pumping rate is reduced leading to a reduction in the equivalent updraft from 3 to $2.5 \mathrm{~ms}^{-1}$. Before 30 seconds, most particles are less than $3 \mu \mathrm{m}$ diameter with $A_{f}<12$, and are larger introduced aerosol particles. The broad swath of particle diameters in panel (f) coincident with $A_{f}>12$ indicates that ice particles are being initiated between 30 and $160 \mathrm{~s}$. The increasing particle diameter trend is modelled well. However up to $300 \mathrm{~s}$, the model overestimates $\mathrm{RH}_{\mathrm{ice}}$ and underestimates the con- densate mass mixing ratio. Since the model total water mixing ratio is constrained to follow the measured values (from the $\mathrm{MBW}$ ), this suggests that the model ice crystals are growing too slowly after nucleation. This leaves excess water substance in the vapour phase and insufficient condensate. This can result from errors in key factors that control depositional growth rate, such as the ice crystals capacitance and deposition coefficient.

\subsection{Temperature regime II: two ice nucleation modes}

Figure 5 shows the expansion using Asian desert dust (Expansion 28) where the chamber gas temperature decreased 
from $-50^{\circ} \mathrm{C}$ to $-57^{\circ} \mathrm{C}$. The chamber pumping rate is now constant throughout the expansion and the maximum relative humidity is reached before the expansion pumping stops. Ice crystal depositional growth causes the chamber humidity to decrease at $260 \mathrm{~s}$. The SID probe asphericity factor $A_{f}$ (panel e) and estimated diameter (panel f) indicate two distinct ice nucleation modes. The first nucleation mode occurs near the start of the expansion pumping, where conditions are just above ice saturation and is indicated by the light grey vertical shading. The second nucleation mode occurs later, but still below water saturation and is indicated by the dark grey vertical shading. Early, during the ice crystal growth phase, the modelled relative humidity agrees well with the observations, and only when the ice crystals begin to evaporate does the humidity diverge. This is the third in a series of expansions during one day using the same aerosol sample. In the next (expansion 29) there is a more obvious seperation between the nucleation modes and in the earlier expansion 27 the modes overlap.

\subsection{Temperature regime III: two nucleation modes}

Figure 6 shows the expansion using Asian desert dust (Expansion 24) where the chamber gas temperature decreased from $-35^{\circ} \mathrm{C}$ to $-45^{\circ} \mathrm{C}$. The pumping rate leads to an equivalent updraft of around $6 \mathrm{~m} \mathrm{~s}^{-1}$. Similar to expansion 28 from temperature regime II, the SID asphericity and diameter imply two ice nucleation modes. The first nucleation mode occurs near the start of the expansion pumping, where conditions are just above ice saturation and is indicated by the light grey vertical shading, while the second nucleation mode occurs later, but still below water saturation and is indicated by the dark grey vertical shading. For all expansions in this temperature regime, the two ice nucleation modes are not clearly seperated apart from an increase in ice nucleation rate.

6.4 Temperature regime IV: one nucleation mode, liquid water observed

Figure 7 shows the expansion using Asian desert dust (Expansion 19) where the chamber gas temperature decreased from $-20^{\circ} \mathrm{C}$ to $-32^{\circ} \mathrm{C}$. This expansion reaches water saturation and both water drops and ice particles are observed. The chamber pumping rate is very fast and the equivalent updraft is around $10 \mathrm{~m} \mathrm{~s}^{-1}$. The SID asphericity and diameter show that between 110 and $170 \mathrm{~s}$ the chamber is dominated by spherical water drops. At $110 \mathrm{~s}$ the chamber reaches water saturation as shown in panel (d). The SID asphericity and diameters also indicate that ice particles are present during this liquid dominated interval. The ice particles are produced at some time during this liquid dominated interval, not before which implies that water condensation is required for ice initiation for these expansions.
6.5 Ice nucleation characteristics of all chamber expansions

Figure 8 shows the changing environmental conditions inside the chamber and highlights when the ice nucleation is occurring (as for panel (h) in the earlier figures) for all the expansions in each of the four temperature regimes. Each line represents the model humidity and temperature, rather than the measured values. The range over which the first nucleation mode occurs is shown by the thicker light-grey line, the second mode by the dark-grey line. Also shown are lines which characterise homogeneous freezing and immersion freezing parametrisations. The homogeneous freezing lines use the Koop et al. (2000) water activity parametrisation. The lines show the critical humidity at which half the drops freeze in $10 \mathrm{~s}$, for a radius of 0.5 and $5 \mu \mathrm{m}$ assuming ammonium sulphate. The dashed line is from Zuberi et al. (2002) and is the critical ice saturation for freezing of ice in aqueous ammonium sulphate drops with kaolinite and montmorillonite dust inclusions. This line is specific for certain size drops and dust concentrations which are not the same as in these expansions.

Expansions in each of the temperature regimes show different ice nucleation modes. The cold expansions in temperature regimes II and III $\left(-60^{\circ} \mathrm{C}<T_{g}<-40^{\circ} \mathrm{C}\right)$, typically show two ice nucleation modes active over different time intervals. The first nucleation mode starts at low ice supersaturations and may be deposition nucleation. The second mode may also be deposition nucleation onto a subset of the dust particles, or if there is a soluble component forming on the aerosols, immersion or homogeneous freezing. This is discussed in Field et al., 2006. The warm expansions in temperature regime IV $\left(T_{g}>-35^{\circ} \mathrm{C}\right)$, show no ice crystals are initiated before liquid water droplets are formed. The ice nucleation mode is immersion or condensation freezing. The coldest expansions in temperature regime $\mathrm{I}\left(T_{g}<-60^{\circ} \mathrm{C}\right)$ show only one ice nucleation mode which starts at low ice supersaturation and is probably deposition nucleation.

The expansions 22-24 (Asian dust AD1) and 40-41 (Saharan dust SD2) show that the onset of ice nucleation occurs at lower relative humidity for each successive expansion. The expansions 26-29 (Asian dust AD1) show an increased separation between the ice nucleation modes for each successive expansion. During these expansions, there is aerosol processing with the ice forming nuclei being conditioned in some way to nucleate at lower relative humidities after each evaporation.

6.6 Sensitivity of the model-observation agreement to different ice nucleation parametrisations

What is the sensitivity of the model-observation agreement to different more "physically-based" ice nucleation parametrisations and to the crystal growth parameters-crystal capacitance and ice deposition coefficient? Figure 9 shows models 

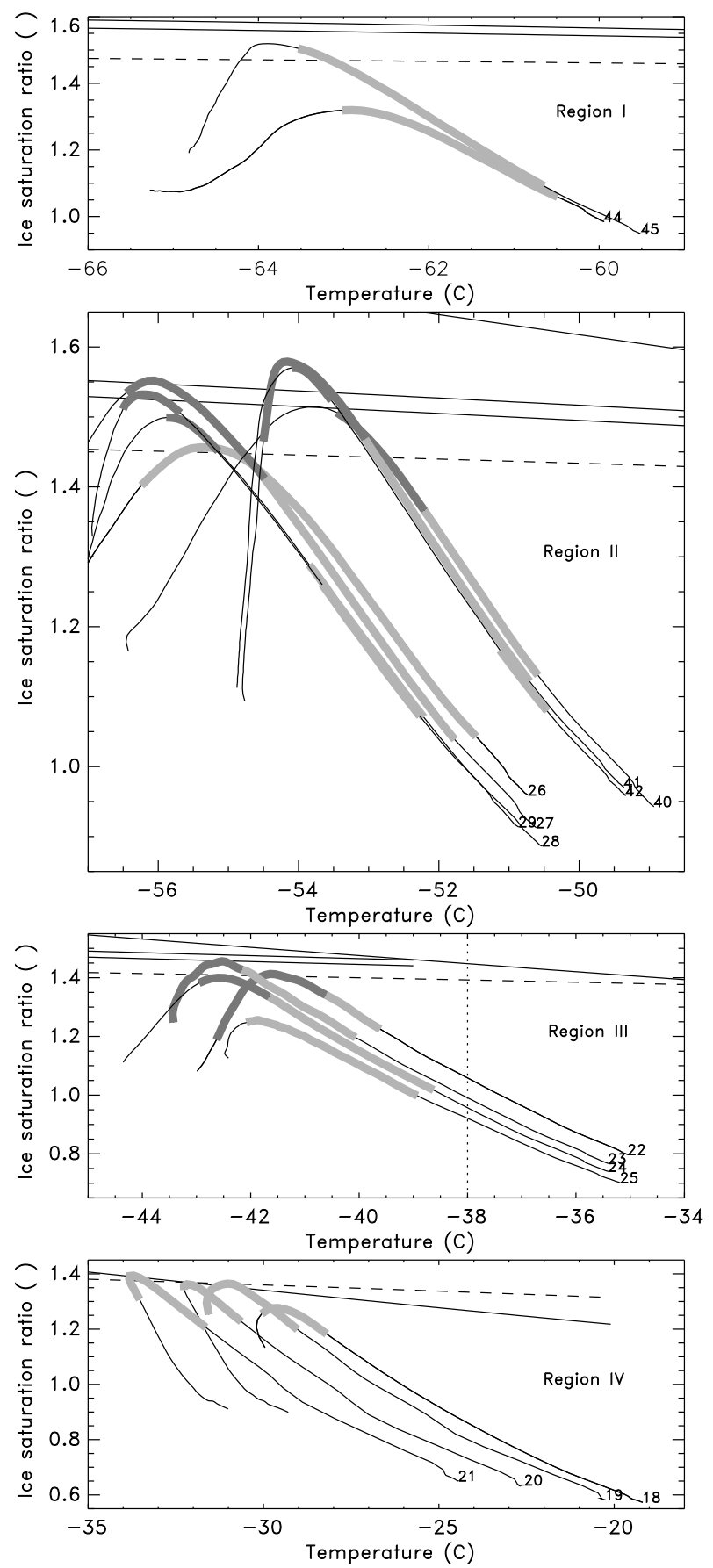

Fig. 8. Chamber temperature and humidity when ice nucleation occurs, indicated by the light- and dark-grey bands. Panels (a)-(d) cover the four temperature regimes I-IV defined in Table 1. The dashed line is immersion-freezing following Zuberi et al. (2002) (micron sized kaolinite particles in 20 to 50 micron ammonium sulphate drops), and the two parallel lines are homogeneous freezing of aqueous ammonium sulphate following Koop et al. (2000) (0.5 and 5 micron sized drops). The single solid line is for water saturation conditions. results for expansion 44 where the chamber temperature starts at $-60^{\circ} \mathrm{C}$ and the relative humidity does not reach the homogeneous freezing threshold. There is only one clear ice nucleation mode, which starts just above ice saturation. The green and red lines are for models parametrising deposition nucleation following Meyers et al. (1992) where the number of ice nuclei are increased (by a factor of 1000) to give the observed final ice concentration. This increase is just because the initial aerosol concentration that is inserted into the chamber is not representative of the atmosphere. The difference between these models is the value of the ice crystal capacitance $(C=1$ for the green line, and $C=0.8$ for the red). Decreasing the capacitance slows the ice crystal growth, enabling higher ambient humidities, which in turn leads to higher ice crystal concentrations. The relative humidity rises above what is observed. This might suggest that the depositional growth rate in the model is too small (and could be increased by changing the capacitance value or the accommodation coefficient). However, the unknown scale factor was abritrarily set, so the final ice crystal concentration will not give any information regarding the capacitance. The mustard line represents the model when ice nucleation is parametrised following Möhler et al. (2006) which fits the observed nucleation rate to

$\frac{d n_{\text {ice }}}{d t}=n_{a} a \frac{d S_{i}}{d t}$

where $n_{a}$ is the aerosol particle concentration, $S_{i}$ is the ice relative humidity and $a$ is a fit parameter. This nucleation is only active above some threshold ice relative humidity $S_{0}$. For expansion $44, a=1.7$ and $S_{0}=1.0$. This gives a much better fit to the relative humidity, mean particle diameter and ice crystal concentrations. The ability to discriminate between different ice nucleation parametrisations is also dependant on knowing the SID ice crystal size threshold. Figure 9c shows, for each model run, two concentrations. One is for all ice crystals and the other for ice crystals greater than $3 \mu \mathrm{m}$ diameter. The low temperatures and therefore low crystal growth rates for this expansion, means that the uncertainty in SID size threshold affects the discrimination much more than warmer, more humid homogeneous freezing expansions.

The sensitivity of the model-observation agreement to different ice deposition coefficients and ice crystal capacitances is shown in Fig. 10. The total ice water content and the resultant relative humidity are sensitive to these crystal growth parameters.

\section{Conclusions}

The AIDA cloud simulation chamber enables the onset of ice nucleation to be clearly observed (as shown in Haag et al., 2003 and Field et al., 2006). Desert dust samples from Sahara and Asia were tested in multiple chamber expansions between $-20^{\circ} \mathrm{C}$ and $-60^{\circ} \mathrm{C}$. The ice nucleation characteristics were varied. For many expansions, two separate ice 

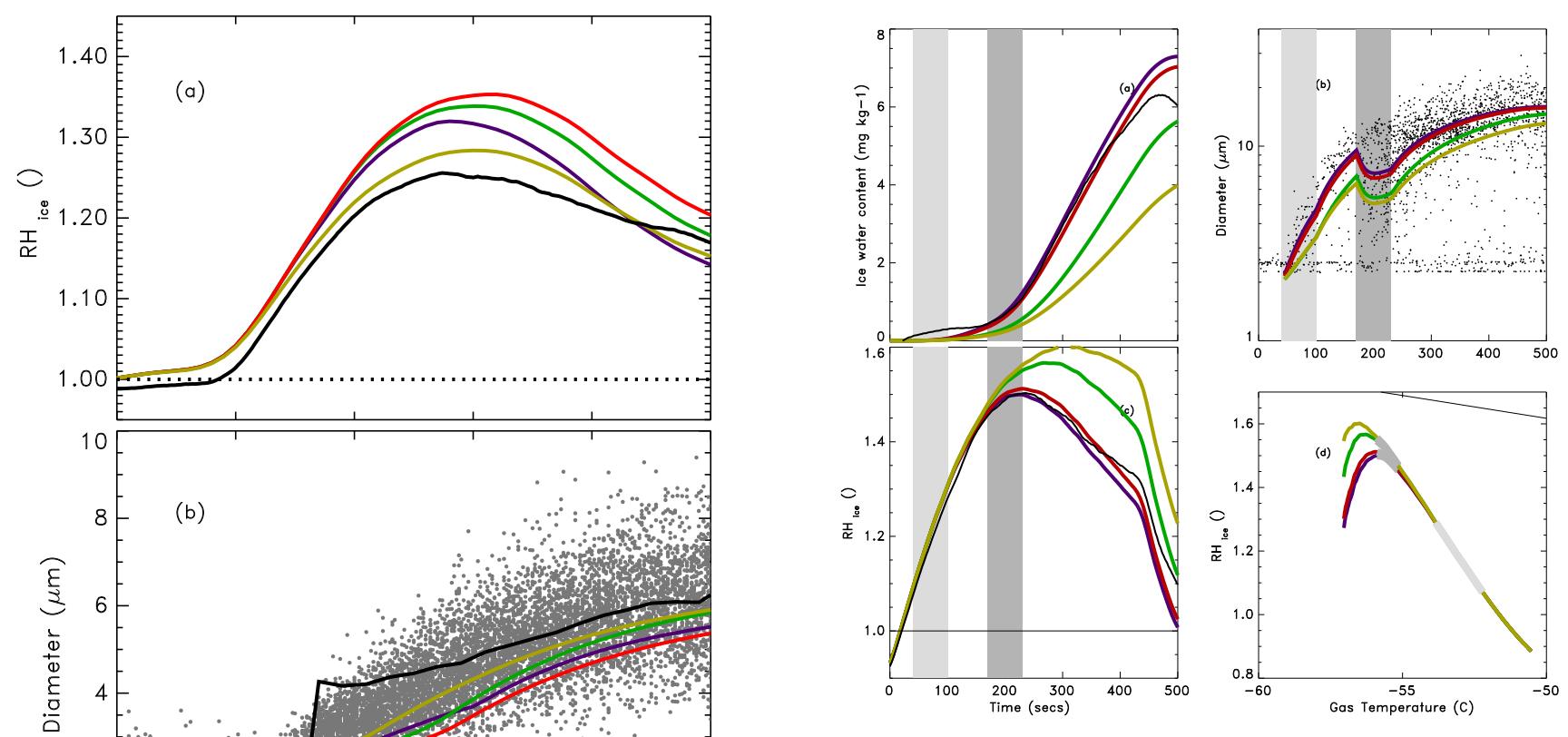

Fig. 10. Expansion 28 (Asian dust AD1) with initial chamber temperature $-50^{\circ} \mathrm{C}$, reaching $-57^{\circ} \mathrm{C}$. There are four model runs each with a different ice deposition coefficient or crystal capacitance. For each model run, the same number of ice particles are inserted during the intervals highlighted by the two grey bands. The black line represents the observations (for the diameter, it is the median of all particles with a diameter greater than $3 \mu \mathrm{m}$ ). The red line is for the default deposition coefficient of 0.24 . The purple line is for a higher deposition coefficient of 1.0. This has the highest growth rate. The green line is for a low deposition coefficient of 0.05. All these three model runs have the default ice crystal capacitance of 1.0. For the final model run in mustard, the crystal capacitance is reduced to 0.5 . The growth rate is now too low and the resultant relative humidity too high.

ature. The heat flux is a simple parametrisation while the water flux uses the measured total water as a constraint. The model then partitions the water between vapour and condensate according to microphysics assumptions. In order to test the self-consistency of the observations and to better determine the relative humidity, ice particles where added to the model as a function of time so as to reproduce the SID particle number concentration, rather than initiating ice particles by means of explicit nucleation acting on aerosol. The model reproduces the observations for all expansions very well. The temperature and relative humidity conditions over which ice nucleation is occurring and the number concentration and size of ice crystals are all well specified.

Future work will include running the model with improved ice nucleation parametrisations developed from these and later measurements. The later measurements include the ice nucleating ability of dust particles with soluble coating. For these later measurements, a new version of the SID probe with lower noise and better shape discrimination will be used. 
Edited by: T. Koop

\section{References}

Cotton, R. J. and Field, P. R.: Ice nucleation characteristics of an isolated wave cloud, Quart. J. Royal Meterol. Soc., 128, 24172437, 2002.

Cziczo, D. J., Murphy, D. M., Hudson, P. K., and Thomson, D. S.: Single particle measurements of the chemical composition of cirrus ice residual during CRYSTAL-FACE, J. Geophys. Res., 109, D04201, doi:10.1029/2003JD004032, 2004.

DeMott, P. J., Sassen, K., Poellot, M. R., Baumgerdner, D., Rogers, D. C., Brooks, S. D, Prenni, A. J., and Kreidenweis, S. M.: African dust aerosols as atmospheric ice nuclei, Geophys. Res. Lett., 30(14), 1732, doi:10.1029/2003GL017410, 2003

Field, P. R., Cotton, R. J., Noone, K., Glantz, P., Kaye, P., Hirst, E., Greenaway, R. S., Jost, C., Gabriel, R., Reiner, T., Andreae, M., Saunders, C. P. R., Archer, A., Choularton, T., Smith, M., Brooks, B., Hoell, C. Bandy, B., Johnson, D., and Heymsfield, A.: Ice nucleation in orographic wave clouds: Measurements made during INTACC, Quart. J. Royal Meterol. Soc., 127, 1493-1512, 2001.

Field, P. R., Möhler, O., Connolly, P., Kraemer, M., Cotton, R., Heymsfield, A. J, Saathoff, H., and Schnaiter, M.: Some ice nucleation charateristics of Asian and Saharan desert dust, Atmos. Chem. Phys., 6, 2991-3006, 2006,

http://www.atmos-chem-phys.net/6/2991/2006/.

Jensen, E. J., Toon, O. B., Tabazadeh, A., Sachse, G. W., Anderson, B. E., Chan, K. R., Twohy, C. W., Gandrud, B., Aulenbach, S. M., Heymsfield, A., Hallet, J., and Gary, B.: Ice nucleation processes in upper tropospheric wave-clouds observed during SUCCESS, Geophys. Res. Lett., 25, 1363-1366, 1998

Kärcher, B. and Lohmann, U.: A parametrization of cirrus cloud formation: Heterogeneous freezing, J. Geophys. Res., 108, 4402, doi:10.1029/2002JD003220, 2003.

Koop, T., Luo, B. P., Tsias, A., and Peter, T.: Water activity as the determinant for homogeneous ice nucleation in aqueous solutions, Nature, 406, 611-614, 2000

Haag, W., Kärcher, B., Schaefers, S., Stetzer, O., Möhler, O., Schurath, U., Krämer, M., and Schiller, C.: Numerical simulations of homogeneous freezing processes in the aerosol chamber AIDA, Atmos. Chem. Phys., 3, 195-210, 2003, http://www.atmos-chem-phys.net/3/195/2003/.

Hallet, J. and Mossop, S., C.: Production of secondary ice crystals during the riming process, Nature, 249, 26-28, 1974.

Heymsfield, A. J., Miloshevich, L. M., Twohy, C., Sachse, G., and Oltmans, S.: Upper troposheric relative humidity observations and implications for cirrus ice nucleation, Geophys. Res. Lett., 25, 1343-1346, 1998.

Hirst, E., Kaye, P. H., Greenaway, R. S., Field, P. R., and Johnson, D. W.: Discrimination of micrometre-sized ice and supercooled droplets in mixed phase clouds, Atmos. Environ., 35, 33 47, 2001.
Lin, R. L., Starr, D. O., DeMott, P. J., Cotton, R. J., Sassen, K., Jenson, E.,Karcher, B., and Liu, X.: Cirrus parcel model comparison project phase 1: The critical components to simulate cirrus initiation explicitly, J. Atmos. Sci., 59(15), 2305-2329, 2002.

Meyers, M. P., DeMott, P. J., and Cotton, W. R.: New primary icenucleation parameterizations in an explicit cloud model, J. Appl. Meteorol., 31, 708-721, 1992.

Möhler, O., Stetzer, O., Schaefers, S., Linke, C., Schnaiter, M., Tiede, R., Saathoff, H., Kraemer, M., Mangold, A., Budz, P., Zink, P., Schreiner, J., Mauersberger, K., Haag, W., Karcher, B., and Schurath, U.: Experimental investigation of homogeneous freezing of sulphuric acid particles in the aerosol chamber AIDA, Atmos. Chem. Phys., 3, 211-223, 2003, http://www.atmos-chem-phys.net/3/211/2003/.

Möhler, O., Büttner, C., Linke, C., Schnaiter, M., Saathoff, H., Stetzer, O., Wagner, R., Krämer, M., Mangold, A., Ebert, V., and Schurath, U.: Effect of sulphuric acid coating on heterogeneous ice nucleation by soot aerosol particles, J. Geophys. Res., 110, D11210, doi:10.1029/2004JD005169, 2005

Möhler, O., Field, P. R., Connolly, P., Benz, S., Saathoff, H., Wagner, M., Cotton, R., Kraemer, M., Mangold, A., and Heymsfield, A. J.: Efficiency of the deposition mode ice nucleation on mineral dust particles, Atmos. Chem. Phys., 6, 3007-3021, 2006, http://www.atmos-chem-phys.net/6/3007/2006/.

Murphy, D., M. and Koop, T.: Review of the vapour pressures of ice and supercooled water for atmospheric applications, Quart. J. Royal Meterol. Soc., 131, 1539-1565, 2005.

Roberts, P. and Hallet, J.: A laboratory study of the ice nucleating properties of some mineral particulates, Quart. J. Royal Meteorol. Soc., 94, 25-34, 1968.

Sassen, K., DeMott, P. J., Prospero, J. M., and Poellet, M. R.: Saharan dust storms and indirect aerosol effects on clouds: CRYSTAL-FACE results, Geophys. Res. Lett., 30(12), 1633, doi:10.1029/2003GL017371, 2003.

Sassen, K., DeMott, P. J., Prospero, J. M., and Poellet, M. R.: Saharan dust storms and indirect aerosol effects on clouds: CRYSTAL-FACE results, Geophys. Res. Lett., 30(12), 1633, doi:10.1029/2003GL017371, 2003.

Seifert, M., Strom, J., Krejci, R., Minikin, A., Petzold, A., Gayet, J. F., Schumann, U., and Ovarlez, J.: In situ observations of aerosol particles remaining from evaporated cirrus crystals: Comparing clean and polluted air masses, Atmos. Chem. Phys., 3, 1037-1049, 2003, http://www.atmos-chem-phys.net/3/1037/2003/.

Targino, A. C., Krejci, R., Noone, K. J., and Glantz, P.: Single particle analysis of ice crystal residuals observed in orographic wave clouds over Scandinavia during INTACC experiment, Atmos. Chem. Phys., 6, 1977-1990, 2006, http://www.atmos-chem-phys.net/6/1977/2006/.

Zuberi, B., Bertram, A. K., Cassa, C. A., Molina, L. T., and Molina, M. J.: Heterogeneous nucleation of ice in $\left(\mathrm{NH}_{4}\right)_{2} \mathrm{SO}_{4}-\mathrm{H}_{2} \mathrm{O}$ particles with mineral dust immersions, Geophys. Res. Lett., 29(10), 1504, doi:10.1029/2001GL014289, 2002. 